\title{
Identification of Phosphorus Stress Related Proteins in the Seedlings of Dongxiang Wild Rice (Oryza Rufipogon Griff.) Using Label-Free Quantitative Proteomic Analysis
}

\author{
Qianwen Deng ${ }^{1,2}$, Liangfang Dai ${ }^{1}$, Yaling Chen ${ }^{1}$, Decai Wu ${ }^{1}$, Yu Shen ${ }^{1}$, Jiankun Xie ${ }^{1}$ and Xiangdong Luo ${ }^{1, *}$ \\ 1 College of Life Science, Jiangxi Normal University, Nanchang 330022, China; dqwsmile@zju.edu.cn (Q.D.); \\ dailf79@163.com (L.D.); yaqing620@163.com (Y.C.); libaibuhecha@163.com (D.W.); \\ sheny202112@163.com (Y.S.); xiejiankun11@163.com (J.X.) \\ 2 College of Agriculture \& Biotechnology, Zhejiang University, Hangzhou 310058, China \\ * Correspondence: xdluolf@163.com
}

check for updates

Citation: Deng, Q.; Dai, L.; Chen, Y.; Wu, D.; Shen, Y.; Xie, J.; Luo, X. Identification of Phosphorus Stress Related Proteins in the Seedlings of Dongxiang Wild Rice (Oryza Rufipogon Griff.) Using Label-Free Quantitative Proteomic Analysis. Genes 2022, 13, 108. https:/ / doi.org/ 10.3390/genes 13010108

Academic Editor: Kejian Wang

Received: 6 December 2021

Accepted: 31 December 2021

Published: 4 January 2022

Publisher's Note: MDPI stays neutral with regard to jurisdictional claims in published maps and institutional affiliations.

Copyright: (c) 2022 by the authors. Licensee MDPI, Basel, Switzerland. This article is an open access article distributed under the terms and conditions of the Creative Commons Attribution (CC BY) license (https:// creativecommons.org/licenses/by/ $4.0 /)$.

\begin{abstract}
Phosphorus (P) deficiency tolerance in rice is a complex character controlled by polygenes. Through proteomics analysis, we could find more low $\mathrm{P}$ tolerance related proteins in unique $\mathrm{P}$ deficiency tolerance germplasm Dongxiang wild rice (Oryza Rufipogon, DXWR), which will provide the basis for the research of its regulation mechanism. In this study, a proteomic approach as well as joint analysis with transcriptome data were conducted to identify potential unique low P response genes in DXWR during seedlings. The results showed that 3589 significant differential accumulation proteins were identified between the low $\mathrm{P}$ and the normal $\mathrm{P}$ treated root samples of DXWR. The degree of change was more than 1.5 times, including 60 up-regulated and 15 downregulated proteins, 24 of which also detected expression changes of more than 1.5-fold in the transcriptome data. Through quantitative trait locus (QTLs) matching analysis, seven genes corresponding to the significantly different expression proteins identified in this study were found to be uncharacterized and distributed in the QTLs interval related to low P tolerance, two of which (LOC_Os12g09620 and LOC_Os03g40670) were detected at both transcriptome and proteome levels. Based on the comprehensive analysis, it was found that DXWR could increase the expression of purple acid phosphatases (PAPs), membrane location of $\mathrm{P}$ transporters (PTs), rhizosphere area, and alternative splicing, and it could decrease reactive oxygen species (ROS) activity to deal with low P stress. This study would provide some useful insights in cloning the P-deficiency tolerance genes from wild rice, as well as elucidating the molecular mechanism of low P resistance in DXWR.
\end{abstract}

Keywords: Dongxiang wild rice; label-free quantitative proteomic; low phosphorus stress; seedling

\section{Introduction}

Phosphorus $(\mathrm{P})$ is one of the essential macronutrients in plant growth and development. It is estimated that $43 \%$ (about 5.8 billion $\mathrm{hm}^{2}$ ) of the world's arable land is deficient in $\mathrm{P}$, and $3 / 4$ farmlands (about 67 million $\mathrm{hm}^{2}$ ) have $\mathrm{P}$ shortages in China, which can result in yield reduction by $5-15 \%$ (about $25-75$ billion $\mathrm{kg}$ ) [1]. Although soil available P deficiency can be improved by applying phosphate $(\mathrm{Pi})$ fertilizer, the utilization rate of which plants apply it is no more than $20 \%$ [2]. This is because most of $P$ in soil exists in the form of insoluble mineral $\mathrm{P}$ or bound organic $\mathrm{P}$, which cannot be absorbed by plants. In addition, the main source of Pi fertilizer is Pi rock, which is a non-renewable resource and is expected to be depleted soon, and the heavy use of Pi fertilizer can also cause environmental problems such as eutrophication of water [3].

Plant adaptation to a P-deficiency environment covers a series of gene expression and morphophysiological events [4], such as regulation of P transporters (PTs), mycorrhizal association, phosphatase secretion, organic acid exudation, and alteration in root structure [5]. Studies have shown that OsPHR2 (Phosphate Starvation Response 2), homologous to PHR1 
in Arabidopsis, is a major transcriptional regulator of low $\mathrm{P}$ response in rice [6,7], which could activate the Pi starvation-induced genes including PHT1 (Phosphate Transporter 1) members by binding to the P1BS (PHR1 Binding Sequence; GNATATNC) motif presented in genes' promoter region [8-13].

P-deficiency tolerance, however, is a complex quantitative trait controlled by many genes and is profoundly influenced by the environment [14]. Quantitative trait locus (QTLs) analysis of P-deficiency tolerance related traits in rice showed that there were generated dozens of QTLs in different populations. These QTLs extensively distributed on chromosomes 1, 2, 3, 4, 6, 7, 9, and 12, especially on chromosomes 4, 6, 11, and 12 [15-17]. Under different genetic backgrounds, the QTL loci of some related traits overlapped or were adjacent on the same chromosome, indicating that the traits related to low P tolerance had greater heritability.

Based on the results of QTL mapping or fine mapping, Wasaki et al. [18] cloned an OsPI1 gene on rice chromosome 1; Yi et al. [19] successfully cloned and verified a transcription factor OsPTF1 that could significantly improve P efficiency in plants; Chin et al. [15] used the molecular marker closely linked to Pup1 for assisted breeding, and Gamuyao et al. [20] successfully cloned the PSTOL1 gene. Wissuwa et al. [21] detected $20 \mathrm{P}$ utilization related locus in rice through genome-wide association analysis and identified a candidate gene on chromosome 1 through comparative variation and expression analysis. Meanwhile, some researchers (including our group) constructed interspecific hybrid population with close wild rice and obtained major QTLs for low P tolerance of wild rice, as well as created some new germplasm [22,23], which broadened the genetic diversity of $\mathrm{P}$ efficient uptake and utilization in rice and laid an important foundation for the utilization of $\mathrm{P}$ efficient genes in wild rice. Therefore, excavating the high efficiency P utilization gene of the crop itself will provide insights in solving the yield problem caused by P deficiency and cultivating new varieties resistant to low $P$.

Dongxiang wild rice (hereinafter referred to as DXWR) is a common wild rice (O. rufipogon Griff.) found in the northernmost distribution latitude to date. It has more abundant genetic diversity than cultivated rice and contains a large number of excellent genes, including low $\mathrm{P}$ tolerance genes, some of which do not even exist in cultivated rice [23-26]. Therefore, DXWR is a valuable resource for the excavation and utilization of low P resistant genes. So far, some QTLs related to low P stress tolerance have been identified in DXWR [23]. In order to understand the molecular mechanism related to low $\mathrm{P}$ resistance of DXWR, we detected many important differentially expressed genes associated with P-deficiency tolerance by transcriptome analysis [26]. However, how DXWR copes with P-deficiency at the protein level is still unclear.

Label-free proteomics analysis is a method that can not only retain the authenticity of the sample to the greatest extent without relying on isotope labeling, but also can compare proteomes affected by different physiological conditions at the same time. Therefore, in this study, we used label-free proteomics analysis to detect the response of DXWR at the protein level under low P stress, and we combined it with the previous transcriptome data to further explore the low $\mathrm{P}$ tolerance genes in DXWR. These results would provide insights in explaining the molecular mechanism of low P resistance, as well as cloning and utilizing the P-deficiency genes from wild rice.

\section{Materials and Methods}

\subsection{Plant Materials and Phosphorus Deficiency Treatment}

In the present study, DXWR from Jiangxi academy of agricultural sciences was carried out as experimental material. The DXWR seeds were surface sterilized using mixed solutions of $\mathrm{NaClO}(10 \%)$ for $15 \mathrm{~min}$ and soaked in petri dishes containing $20 \mathrm{~mL}$ deionized water at room temperature for 3 days. Then, the seeds were selected with the same growth trend and planted in the plastic pot containing quartz sand in a climate control chamber at day/night $14 \mathrm{~h} / 10 \mathrm{~h}\left(30^{\circ} \mathrm{C} / 26^{\circ} \mathrm{C}\right)$ [26]. A $1 / 2$ Yoshida culture medium (pH 5.8) was added once for growth when germinated seeds had coleoptiles $10 \mathrm{~mm}$ approximately in 
length [27]. At the emergence of the third leaf (about 15 days), plants were transferred into either a culture medium with low $\mathrm{P}$ concentration $\left(0.016 \mathrm{mM} \mathrm{NaH}_{2} \mathrm{PO}_{4}\right)$ or normal $\mathrm{P}$ concentration $\left(0.32 \mathrm{mM} \mathrm{NaH}_{2} \mathrm{PO}_{4}\right)$, which corresponded to the $-\mathrm{P}$ treatments (RLP) and $+\mathrm{P}$ treatments $(\mathrm{RCK})$, respectively. The culture medium was replaced every three days. There were 20 seedlings per treatment with three biological replications. Roots were harvested at 9 days after the experimental treatments started, and the samples were frozen immediately using liquid nitrogen and stored at $-80^{\circ} \mathrm{C}$ for further analyzing. Root samples of cultivated rice Nipponbare (NP) were obtained in the same way at the same time and used to determine the expression of OsPHR2, OsPHR1, OsPHO2 (Phosphate2), and OsPHO1 (Phosphate Transporter 1), as well as its natural reverse transcripts (Cis-Natural Antisense Transcripts, NATs).

\subsection{Protein Extraction and Enzymatic Hydrolysis}

Root proteins of six DXWR samples were extracted using trichloroacetic acid (TCA)acetone precipitation method [28]. Briefly, the sample was ground into powder in liquid nitrogen and then suspended in extraction buffer ( $8 \mathrm{M}$ urea, $1 \%$ DTT, $0.1 \mathrm{M}$ Tris-HCl, $\mathrm{pH} 8.8$, $1 \%$ complete protease inhibitors (Roche, Mannheim, Germany)). Repeated vortex of the sample and then removal of insoluble precipitation was performed by centrifugation at $14,000 \times g$ for $40 \mathrm{~min}$. The supernatant was precipitated overnight with $20 \%(v / v)$ TCA, washed three times with cold acetone, and solubilized in extraction buffer. All operations were performed at low temperatures. The protein concentration was measured using the BCA Protein Assay Kit (Bio-Rad, Hercules, CA, USA). The final concentration of urea in protein solution was adjusted to $2 \mathrm{M}$ with $40 \mathrm{mM} \mathrm{NH}_{4} \mathrm{HCO}_{3}$ solution. An amount of $4 \mu \mathrm{g}$ trypsin (Promega, Madison, WI, USA) was added to each sample containing $200 \mu \mathrm{g}$ protein and incubated overnight at $37^{\circ} \mathrm{C}$ following the instructions of the manufacturer.

\subsection{Liquid Chromatography and Tandem Mass Spectrometry Proteomics Analysis (LC-MS/MS) of the RLK and RCK Samples}

LC-MS/MS analysis was performed on a Q-Exactive mass spectrometer (Thermo Fisher Scientific, Waltham, MA, USA) that was coupled to an Easy nLC Biosystem (Thermo Fisher Scientific, Waltham, MA, USA) with the help provided by Shanghai Applied Protein Technology (Shanghai, China). Balance chromatographic column with buffer A ( $0.1 \%$ formic acid, $3 \%$ acetonitrile and $97 \% \mathrm{H}_{2} \mathrm{O}$ ). Each sample was automatically injected into the prepacked column $\left(2 \mathrm{~cm} \times 100 \mu \mathrm{m} 3 \mu \mathrm{m}-\mathrm{C}_{18}\right)$, then flowed into an analytical column $\left(10 \mathrm{~cm} \times 75 \mu \mathrm{m} 3 \mu \mathrm{m}-\mathrm{C}_{18}\right)$ at a speed of $250 \mathrm{~nL} / \mathrm{min}$ controlled by intelliflow technology. After that, the sample was separated with a linear gradient of buffer B from $6 \%(80 \%$ acetonitrile, $0.08 \%$ formic acid) to $95 \%$ over $116 \mathrm{~min}$ and then followed by an equilibration of the column at $6 \%$ buffer B for $4 \mathrm{~min}$. MS/MS spectra were searched using MaxQuant software (version 1.5.3.17) against the UniProt proteome database (Uniport_Oryza sativa_168264_20171201.fasta), and the label-free quantitation algorithm was performed for quantitative analysis. The maximum missed cleavages used for the database search were set to 2 . The mass tolerance was set to $20 \mathrm{ppm}$ on full scans. For label-free quantitative methods, retention time matching between runs was performed within a time window of $2 \mathrm{~min}$. The peptide false discovery rate (FDR) and protein FDR did not exceed 0.01. This rigorous analysis tool named Andromeda was used for analysis-obtained excellent peptide score distribution to judge the quality of MS experimental data [29]. Quantifiable proteins were defined as those identified at least twice in the three biological replicates. Proteins with an adjusted $p$ value $<0.05$ were assigned as differentially expressed between the RLK and RCK samples [30].

\subsection{Bioinformatics Analysis}

With the help provided by Shanghai Applied Protein Technology (Shanghai, China), bioinformatics analysis was performed on the obtained proteome data. First, we searched the EBI database for conserved motifs that matched the target protein through Inter- 
ProScan [31] and annotated the motif-related functional information to the target protein sequence to achieve gene ontology (GO) functional annotation [32,33]. Then, proteins were matched to the Kyoto encyclopedia of genes and genomes (KEGG) database to obtain the pathway they might participate in. Last but not least, proteome data set was used to construct protein-protein interaction (PPI) network by using STRING (https://cn.string-db.org/), and the parameter was set to moderate confidence (0.400).

\subsection{Gene Expression Analysis by Quantitative Real-Time PCR ( $q$ RT-PCR)}

For qRT-PCR analysis, total RNA in roots samples were isolated using TRIzol reagent (Invitrogen, Carlsbad, CA, USA) according to the manufacturer's protocol. The first cDNA was synthesized with $2 \mu \mathrm{g}$ of total RNA, using ReverTra Ace ${ }^{\circledR}$ qPCR RT Master Mix with gDNA Remover (TOYOBO, Osaka, Japan). Briefly, RNA was pre-denatured at $65^{\circ} \mathrm{C}$, and gDNA was removed by adding DN Master Mix with gDNA Remover at $37^{\circ} \mathrm{C}$ for 5 min. The first strand cDNA was synthesized by using RT Master Mix through the following three-step reaction: $37^{\circ} \mathrm{C}$ for $15 \mathrm{~min}, 50{ }^{\circ} \mathrm{C}$ for $5 \mathrm{~min}$, and $98{ }^{\circ} \mathrm{C}$ for $5 \mathrm{~min}$. Then, synthesized cDNAs were used as templates for qRT-PCR with THUNDERBIRD ${ }^{\mathrm{TM}}$ SYBR $^{\circledR}$ qPCR Mix (TOYOBO, Osaka, Japan) and the LightCycler ${ }^{\circledR} 96$ instrument (Roche, Mannheim, Germany) according to the manufacturer's manuals. The conditions of the qRTPCR reaction are set as follows: $95^{\circ} \mathrm{C}$ for $30 \mathrm{~s}$ with 1 cycle for pre-denaturation; two-step reaction with 40 cycles of $10 \mathrm{~s}$ at $95^{\circ} \mathrm{C}$ and $30 \mathrm{~s}$ at $60^{\circ} \mathrm{C}$ for amplification; three-step reaction for melt curve stage with $95^{\circ} \mathrm{C}$ for $10 \mathrm{~s}, 65^{\circ} \mathrm{C}$ for $60 \mathrm{~s}$, and $97^{\circ} \mathrm{C}$ for $1 \mathrm{~s} ; 37^{\circ} \mathrm{C}$ for $30 \mathrm{~s}$ for cooling. OsActin1 (LOC_Os03g50885) was used as an internal control [34]. The $2^{-\Delta \Delta C t}$ method was used for relative quantification. The statistical significance was evaluated by $t$-test analysis. The primers used are listed in Supplementary Table S1.

\subsection{Conjoint Analysis of Proteomic and Transcriptomics Related to Low P Stress}

We selected the DXWR root transcriptome data obtained from samples treated at the same time with this study for comparison [26], and we screened the transcriptome data with the gene expression change fold $\geq 1.5$ times and $p$ value $\leq 0.05$ after low P treatment for analysis.

\section{Results}

\subsection{Label-Free Quantitative Proteomic Analysis on DXWR}

By analyzing the peptide scores obtained by MS, the results showed that about $78.22 \%$ of the peptides scored above 60, which meant that the quality of LC-MS/MS experimental data was relatively high (Supplementary Figure S1). Through label-free proteomic data analysis, a total of 4329 protein groups (Supplementary Table S2) and 23,598 peptides (Supplementary Table S3) were identified from six DXWR root samples (RLP and RCK with three biological repetitions, respectively). Among these proteins, we designated 3589 proteins that were detected in at least two replicates as identified proteins (Figure 1a-c). In addition, the clustering analysis of proteins identified in different samples showed that the similarities between the three biological repetitions of the same treatment were high and between the different treatments were very low (Figure 1d). Based on this, it was indicated that changes in expression of these target proteins could represent a significant effect of biological treatment on samples. Using these data, we selected proteins with $\geq 1.5$-fold changes as an additional standard [35], and the volcano pot was drawn by using protein expression fold changes and $p$ value (Figure 1e). The results showed that 60 protein groups were up-regulated (Table 1) and 15 were downregulated (Table 2). Those results indicated that P-deficiency treatment could affect the accumulation of some gene expression products in DXWR. 
a
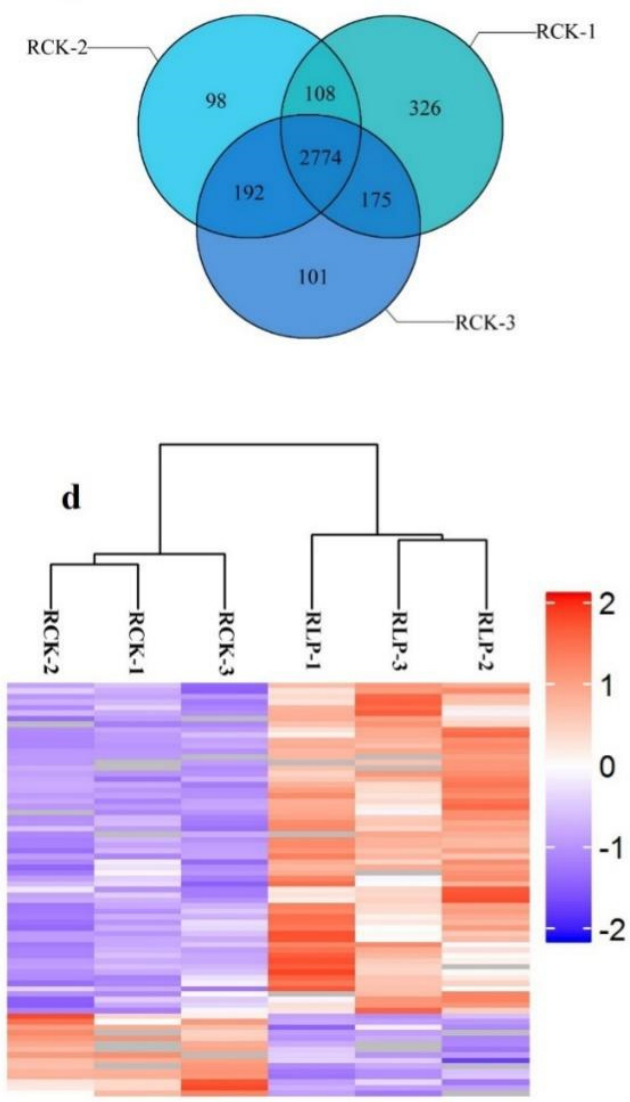

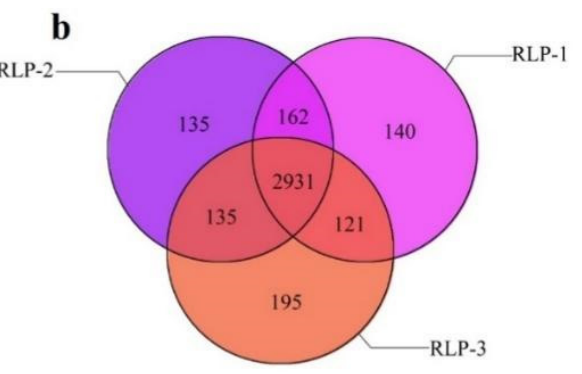

c
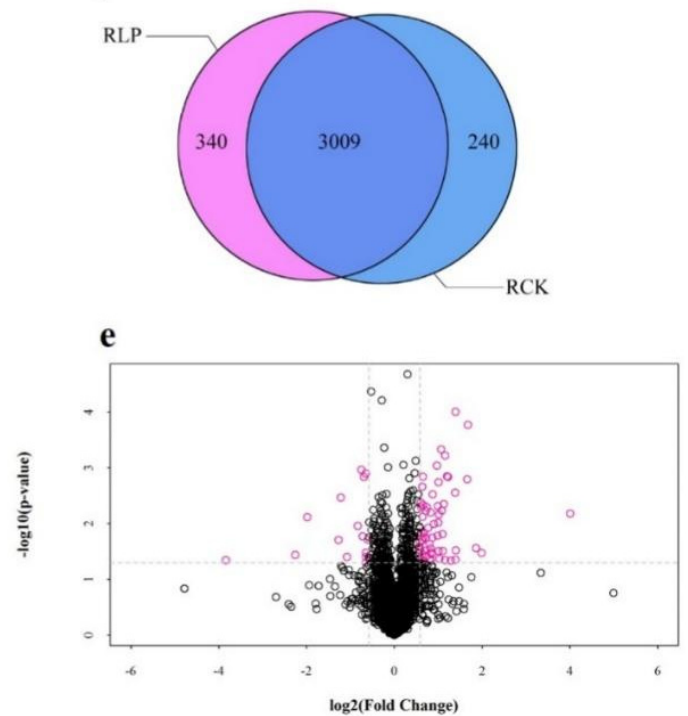

Figure 1. Identification and analysis of proteins that differentially accumulated between RCK and RLP. RLP, roots under low phosphorus stress treatment with three biological repetitions; RCK, roots under phosphorus sufficiency stress treatment with three biological repetitions, same to below. (a) Proteins identified in three RCK repeated materials. (b) Proteins identified in three RLP repeated materials. (c) Proteins identified in RCK and RLP. (d) Clustering analysis of proteins identified in RCK and RLP samples. (e) Volcano pot. The gene expression values were transformed to log2 scale. The protein expression fold change (X-axis) was plotted against the $p$ value obtained from $t$ test $\log 10$-value $(Y$-axis). Small circle represents protein. The red circle represents a protein with a change fold greater than 1.5 .

Table 1. Up-regulated proteins identified from label-free quantitative analysis.

\begin{tabular}{|c|c|c|c|c|c|}
\hline RAP (Os ID) & $\begin{array}{c}\text { MSU } \\
\text { (LOC_Os ID) }\end{array}$ & Description & Gene Name & $\begin{array}{c}\text { Ratio } \\
\text { (RLP/RCK) }\end{array}$ & $p$ Value \\
\hline Os03g0603600 & LOC_Os03g40670 & $\begin{array}{l}\text { Glycerophosphoryl diester } \\
\text { phosphodiesterase family protein }\end{array}$ & OSJNBa0004G03.4 & 16.03000419 & 0.006552 \\
\hline Os03g0150800 & LOC_Os03g05640 & Inorganic phosphate transporter $1-2$ & PTH1-2 & 3.960889785 & 0.033385 \\
\hline Os01g0776600 & LOC_Os01g56880 & Purple acid phosphatase & Os01g0776600 & 3.622714483 & 0.02748 \\
\hline Os10g0444700 & LOC_Os10g30790 & $\begin{array}{c}\text { Probable inorganic phosphate } \\
\text { transporter } 1-8\end{array}$ & PHT1-8 & 3.188357926 & 0.000168 \\
\hline Os12g0637100 & LOC_Os12g44020 & Purple acid phosphatase & LOC_Os12g44020 & 3.158117784 & 0.001597 \\
\hline Os01g0660200 & LOC_Os01g47070 & Glycosyl hydrolase & OsJ_02893 & 2.640670999 & 0.030145 \\
\hline Os03g0719300 & LOC_Os03g51000 & 3,4-dihydroxy-2-butanone kinase & B1377B10.5 & 2.626305612 & 0.0442 \\
\hline Os12g0198000 & LOC_Os12g09620 & Expressed protein & Os12g0198000 & 2.624379146 & $9.82 \times 10^{-5}$ \\
\hline Os08g0434100 & LOC_Os08g33710 & Ribonuclease & & 2.61471967 & 0.002771 \\
\hline Os06g0291100 & LOC_Os06g18790 & Anthocyanidin 3-O-glucosyltransferase & B1026E06.27 & 2.435586728 & 0.046309 \\
\hline Os02g0704900 & LOC_Os02g47600 & Soluble inorganic pyrophosphatase & $I P P$ & 2.329695866 & 0.001458 \\
\hline Os07g0129200 & LOC_Os07g03710 & SCP-like extracellular protein & OsI_22957 & 2.29462251 & 0.001414 \\
\hline Os05g0402900 & LOC_Os05g33400 & Basic 7S globulin precursor & OsJ_18488 & 2.229986706 & 0.045047 \\
\hline Os03g0405900 & LOC_Os03g29240 & Probable nucleoredoxin 1-2 & Os03g0405900 & 2.22151414 & 0.0006 \\
\hline Os07g0630400 & LOC_Os07g43670 & $\begin{array}{l}\text { Ribonuclease T2 family domain } \\
\text { containing protein }\end{array}$ & P0011H09.133 & 2.18513976 & 0.004417 \\
\hline Os10g0538200 & LOC_Os10g39300 & $\begin{array}{c}\text { Aspartic proteinase nepenthesin, } \\
\text { putative, expressed }\end{array}$ & OsI_34482 & 2.147759239 & 0.030829 \\
\hline
\end{tabular}


Table 1. Cont.

\begin{tabular}{|c|c|c|c|c|c|}
\hline RAP (Os ID) & $\begin{array}{c}\text { MSU } \\
\text { (LOC_Os ID) }\end{array}$ & Description & Gene Name & $\begin{array}{c}\text { Ratio } \\
\text { (RLP/RCK) }\end{array}$ & $p$ Value \\
\hline Os01g0357100 & LOC_Os01g25484 & Ferredoxin-nitrite reductase & OsI_01871 & 2.139517104 & 0.015234 \\
\hline Os11g0256050 & LOC_Os11g14950 & $\begin{array}{l}\text { Acetolactate synthase small subunit } \\
\text { Elongation factor Tu family protein, }\end{array}$ & LOC_Os11g14950 & 2.118353002 & 0.005821 \\
\hline Os02g0543300 & LOC_Os02g33850 & $\begin{array}{l}\text { Protein synthesis factor, GTP-binding } \\
\text { domain containing protein }\end{array}$ & OsI_07585 & 2.087060146 & 0.000463 \\
\hline Os07g0549800 & LOC_Os07g36490 & $\begin{array}{l}\text { RNA recognition motif containing } \\
\text { protein }\end{array}$ & OsI_26412 & 2.035407774 & 0.042675 \\
\hline Os03g0738600 & LOC_Os03g52860 & Linoleate 9S-lipoxygenase 2 & LOX1.1 & 2.017839574 & 0.006819 \\
\hline Os10g0191300 & LOC_Os10g11500 & SCP-like extracellular protein & LOC_Os10g11500 & 2.010712464 & 0.0018 \\
\hline Os05g0247100 & LOC_Os05g15770 & Glycoside hydrolase family 18 & $\operatorname{dip} 3$ & 2.004889132 & 0.03089 \\
\hline Os10g0476000 & LOC_Os10g33630 & Adaptin ear-binding coat-associated & Os10g0476000 & 1.997085229 & 0.009577 \\
\hline Os04g0480900 & LOC_Os04g40490 & Glycosyl hydrolase family 5 protein & OsI_16340 & 1.983137882 & 0.00484 \\
\hline NONE & LOC_Os07g23850 & Glycosyl hydrolase & OsI_25770 & 1.977235788 & 0.016379 \\
\hline Os03g0238600 & LOC_Os03g13540 & Purple acid phosphatase & LOC_Os03g13540 & 1.955506958 & 0.0009 \\
\hline Os06g0172800 & LOC_Os06g07600 & Uncharacterized glycosyltransferase & OsJ_20295 & 1.871718049 & 0.010126 \\
\hline Os01g0949900 & LOC_Os01g72150 & Glutathione S-transferase & Os01g0949900 & 1.826722973 & 0.002976 \\
\hline Os03g0405500 & LOC_Os03g29190 & Probable nucleoredoxin 1-1 & Os03g0405500 & 1.822377514 & 0.017644 \\
\hline Os07g0162700 & LOC_Os07g06860 & Gibberellin receptor GID1L2 & P0428D12.107 & 1.818251432 & 0.034418 \\
\hline Os01g0747500 & LOC_Os01g54370 & Dihydropyrimidinase & OsI_03720 & 1.785266614 & 0.046646 \\
\hline Os06g0320000 & LOC_Os06g 21550 & Thioredoxin-like protein Clot & Os06g0320000 & 1.776329132 & 0.032953 \\
\hline Os07g0658600 & LOC_Os07g46480 & $\begin{array}{l}\text { Eukaryotic aspartyl protease domain } \\
\text { containing protein }\end{array}$ & OsJ_25435 & 1.774156573 & 0.006259 \\
\hline Os07g0539900 & LOC_Os07g35560 & $\begin{array}{c}\text { Glucan endo-1,3-beta-glucosidase } \\
\text { precursor }\end{array}$ & OsJ_24595 & 1.773462618 & 0.027652 \\
\hline Os01g0687400 & LOC_Os01g49320 & Chitinase & & 1.760766916 & 0.04272 \\
\hline Os02g0771700 & LOC_Os02g53200 & $\begin{array}{c}\text { Glucan endo-1,3-beta-glucosidase } \\
\text { precursor }\end{array}$ & Os02g0771700 & 1.735448414 & 0.022941 \\
\hline Os07g0186000 & LOC_Os07g08840 & Thioredoxin $\mathrm{H} 1$ & TRXH & 1.701278791 & 0.011916 \\
\hline Os04g0456700 & LOC_Os04g38390 & $\begin{array}{c}\text { Wound/stress protein, putative, } \\
\text { expressed }\end{array}$ & OSJNBa0036B21.4 & 1.667066756 & 0.004973 \\
\hline Os07g0187700 & LOC_Os07g09000 & $\begin{array}{l}\text { WD40 protein, regulation of the plasma } \\
\text { membrane localization of phosphate } \\
\text { transporters, phosphate uptake and } \\
\text { translocation }\end{array}$ & Os07g0187700 & 1.663966106 & 0.037637 \\
\hline Os01g0132000 & LOC_Os01g04050 & $\begin{array}{l}\text { BBTI12-Bowman-Birk type bran trypsin } \\
\text { inhibitor precursor }\end{array}$ & Os01g0132000 & 1.654255218 & 0.017942 \\
\hline Os07g0683600 & LOC_Os07g48460 & $\begin{array}{c}\text { Stress responsive protein, putative, } \\
\text { expressed }\end{array}$ & OsJ_25614 & 1.644255664 & 0.005868 \\
\hline Os03g0106400 & LOC_Os03g01600 & $\begin{array}{c}\text { Branched-chain-amino-acid } \\
\text { aminotransferase }\end{array}$ & LOC_Os03g01600 & 1.610695927 & 0.030361 \\
\hline Os10g0498100 & LOC_Os10g35500 & Epoxide hydrolase & OsJ_32041 & 1.592639094 & 0.014471 \\
\hline Os06g0717900 & LOC_Os06g50390 & Aspartic proteinase nepenthesin II-like & P0541C02.19-1 & 1.585853919 & 0.014796 \\
\hline Os07g0634600 & LOC_Os07g44070 & Pectin acetylesterase & P0455H11.118-1 & 1.583424242 & 0.017612 \\
\hline Os09g0261300 & LOC_Os09g08660 & Phosphoglycolate phosphatase & B1077E10.18-1 & 1.57844691 & 0.004606 \\
\hline Os04g0628200 & LOC_Os04g53640 & Peroxidase & $\operatorname{prx} 56$ & 1.572207357 & 0.001422 \\
\hline Os10g0527800 & LOC_Os10g38360 & Glutathione S-transferase & OsI_34399 & 1.558245126 & 0.045511 \\
\hline Os05g0154800 & LOC_Os05g06280 & U1 small nuclear ribonucleoprotein A & Os05g0154800 & 1.55665498 & 0.007471 \\
\hline Os03g0661600 & LOC_Os03g45960 & $\begin{array}{l}\text { Similar to Alpha-amylase/trypsin } \\
\text { inhibitor (Antifungal protein). }\end{array}$ & OSJNBb0065L20.2 & 1.553387114 & 0.019769 \\
\hline Os03g0214000 & LOC_Os03g11530 & Purple acid phosphatase & LOC_Os03g11530 & 1.550828031 & 0.035302 \\
\hline Os07g0638100 & LOC_Os07g44410 & $\begin{array}{l}\text { WD40-like Beta Propeller Repeat family } \\
\text { protein }\end{array}$ & OJ1340_C08.105 & 1.550189963 & 0.002186 \\
\hline Os10g0530900 & LOC_Os10g38740 & $\begin{array}{c}\text { Probable glutathione S-transferase } \\
\text { GSTU6 }\end{array}$ & GSTU6 & 1.530424487 & 0.014539 \\
\hline Os01g0783500 & LOC_Os01g57450 & $\begin{array}{l}\text { Universal stress protein domain } \\
\text { containing protein }\end{array}$ & Os01g0783500 & 1.526457541 & 0.005096 \\
\hline Os10g0159800 & LOC_Os10g07229 & dehydrogenase & Os10g0159800 & 1.524049105 & 0.049332 \\
\hline Os02g0139100 & LOC_Os02g04650 & Activator of Hsp90 ATPase & Os02g0139100 & 1.511733905 & 0.004122 \\
\hline Os06g0266400 & LOC_Os06g15600 & Similar to chemocyanin Phytocyanin & OsI_22465 & 1.508518489 & 0.04803 \\
\hline Os05g0182100 & LOC_Os05g08930 & $\begin{array}{c}\text { chloroplast lumen common family } \\
\text { protein }\end{array}$ & OsI_18722 & 1.500572906 & 0.021029 \\
\hline Os05g0594900 & LOC_Os05g51650 & $\begin{array}{l}\text { U6 snRNA-associated Sm-like protein } \\
\text { LSm8 }\end{array}$ & Os05g0594900 & 1.50032122 & 0.029511 \\
\hline
\end{tabular}


Table 2. Downregulated proteins identified from label-free quantitative analysis.

\begin{tabular}{|c|c|c|c|c|c|}
\hline RAP (Os ID) & MSU (LOC_Os ID) & Description & Gene Name & $\begin{array}{c}\text { Ratio } \\
\text { (RLP/RCK) }\end{array}$ & $p$ Value \\
\hline Os02g0822800 & LOC_Os02g57690 & Acyl-CoA binding protein-like & Os02g0822800 & 0.657506509 & 0.019206616 \\
\hline Os03g0219200 & LOC_Os03g11960 & copper/zinc superoxide dismutase & Os03g0219200 & 0.637308003 & 0.049986265 \\
\hline Os08g0374000 & LOC_Os08g28670 & Bet v I allergen family protein & Os08g0374000 & 0.636556967 & 0.001251447 \\
\hline Os06g0104300 & LOC_Os06g01490 & monocopper oxidase & Os06g0104300 & 0.636141093 & 0.039078829 \\
\hline Os01g0155600 & LOC_Os01g06290 & Splicing factor, arginine/serine-rich & & 0.635942121 & 0.032973117 \\
\hline Os08g0441500 & LOC_Os08g34280 & $\begin{array}{l}\text { Cinnamoyl-CoA reductase, lignin } \\
\text { formation }\end{array}$ & P0528B09.35-1 & 0.617419753 & 0.001449421 \\
\hline Os05g0278500 & LOC_Os05g19910 & Acyl transferase 5 & AT5 & 0.606305592 & 0.016918153 \\
\hline Os05g0135700 & LOC_Os05g04510 & $\begin{array}{l}\text { S-adenosylmethionine synthase, } \\
\text { catalyzes the formation of } \\
\text { S-adenosylmethionine from } \\
\text { methionine and ATP. }\end{array}$ & sams & 0.59241418 & 0.001074265 \\
\hline Os05g0375400 & LOC_Os05g31140 & Glucanase & GLU & 0.56122895 & 0.010900711 \\
\hline Os02g0620500 & LOC_Os02g40710 & $\begin{array}{l}\text { Ammonium transporter } 1 \\
\text { member } 3\end{array}$ & AMT1-3 & 0.473226337 & 0.03929424 \\
\hline Os01g0717700 & LOC_Os01g52010 & alliin lyase precursor & Os01g0717700 & 0.428345703 & 0.003389562 \\
\hline Os04g0497200 & LOC_Os04g41970 & Endoglucanase 12 & GLU3 & 0.414420949 & 0.019558331 \\
\hline \multirow[t]{2}{*}{ Os01g0264900 } & LOC_Os01g16010 & $\begin{array}{l}\text { BCAS2 protein, putative, expressed } \\
\text { ribulose-1,5-bisphosphate }\end{array}$ & OsI_01292 & 0.253067847 & 0.00757617 \\
\hline & cpDNA & $\begin{array}{c}\text { carboxylase/oxygenase large } \\
\text { subunit, RuBisCO }\end{array}$ & $r b c L$ & 0.208373843 & 0.03601915 \\
\hline Os02g0152700 & LOC_Os02g05880 & $\begin{array}{l}\text { DNA-directed RNA } \\
\text { polymerase subunit }\end{array}$ & OsI_05888 & 0.069922407 & 0.045181841 \\
\hline
\end{tabular}

\subsection{Functional Classification by Gene Ontology (GO)}

To gain insight into the functional roles of the proteins significantly different between the RCK and RLP samples, GO annotation and enrichment was conducted and the results were listed in Supplementary Table S4, schematically represented in three ontologies as molecular function, cellular component, and biological process, as in Figure $2 a$. The enrichment of biological process involved in metabolic process and cellular process was significantly observed. The most significantly enriched molecular function were catalytic activity and binding. Significant enrichment of cellular compartments was identified, including cell part, cell, membrane, membrane part, and organelle part. From the above description, we could give a conjecture that low P stress could affect cell proliferation and enzyme synthesis as well as the ability of cell or membrane to bind to certain stimulus signals in DXWR.

\subsection{Kyoto Encyclopedia of Genes and Genomes (KEGG) Pathway Mapping}

KEGG pathways analysis was performed on the 75 significantly different expression proteins (SDEPs, 60 up-regulated and 15 downregulated) identified in this study (Supplementary Table S5). These proteins were involved in 31 metabolic pathways. U6 snRNA-associated Sm-like protein 8 (LSm8, LOC_Os05g51650, up-regulated), U1 small nuclear ribonucleoprotein A (U1A, LOC_Os05g06280, up-regulated), splicing factor of arginine/serine-rich (SR, LOC_Os01g06290, downregulated), and pre-mRNA-splicing factor SPF27 (BCAS2, LOC_Os01g16010, downregulated) were enriched in the spliceosome pathway which was one of the top 20 KEGG pathways predicted to be affected by low P stress (Figure 2b). Furthermore, branched-chain-amino-acid aminotransferase (BCAT, LOC_Os03g01600, up-regulated) and acetolactate synthase small subunit (ALS, LOC_Os11g14950, up-regulated) were enriched in the pathway of branched-chain amino acids (BCAAs, including valine, leucine, and isoleucine) biosynthesis. Ribulose-1,5-bisphosphate carboxylase/oxygenase large subunit (rbcL, encoded by leucoplast, downregulated) and phosphoglycolate phosphatase (PGP, LOC_Os09g08660, up-regulated) were enriched in the pathway of glyoxylate and dicarboxylate metabolism. A chitinase (LOC_Os01g49320, 
up-regulated) and a glycosyl hydrolase (LOC_Os01g47070, up-regulated) were enriched in amino sugar and nucleotide sugar metabolism. In addition, two GST (LOC_Os10g38740 and LOC_Os10g38360, up-regulated) proteins were enriched in the glutathione pathway. These results indicated that genes involved in these pathways might respond to low $\mathrm{P}$ stress in DXWR.
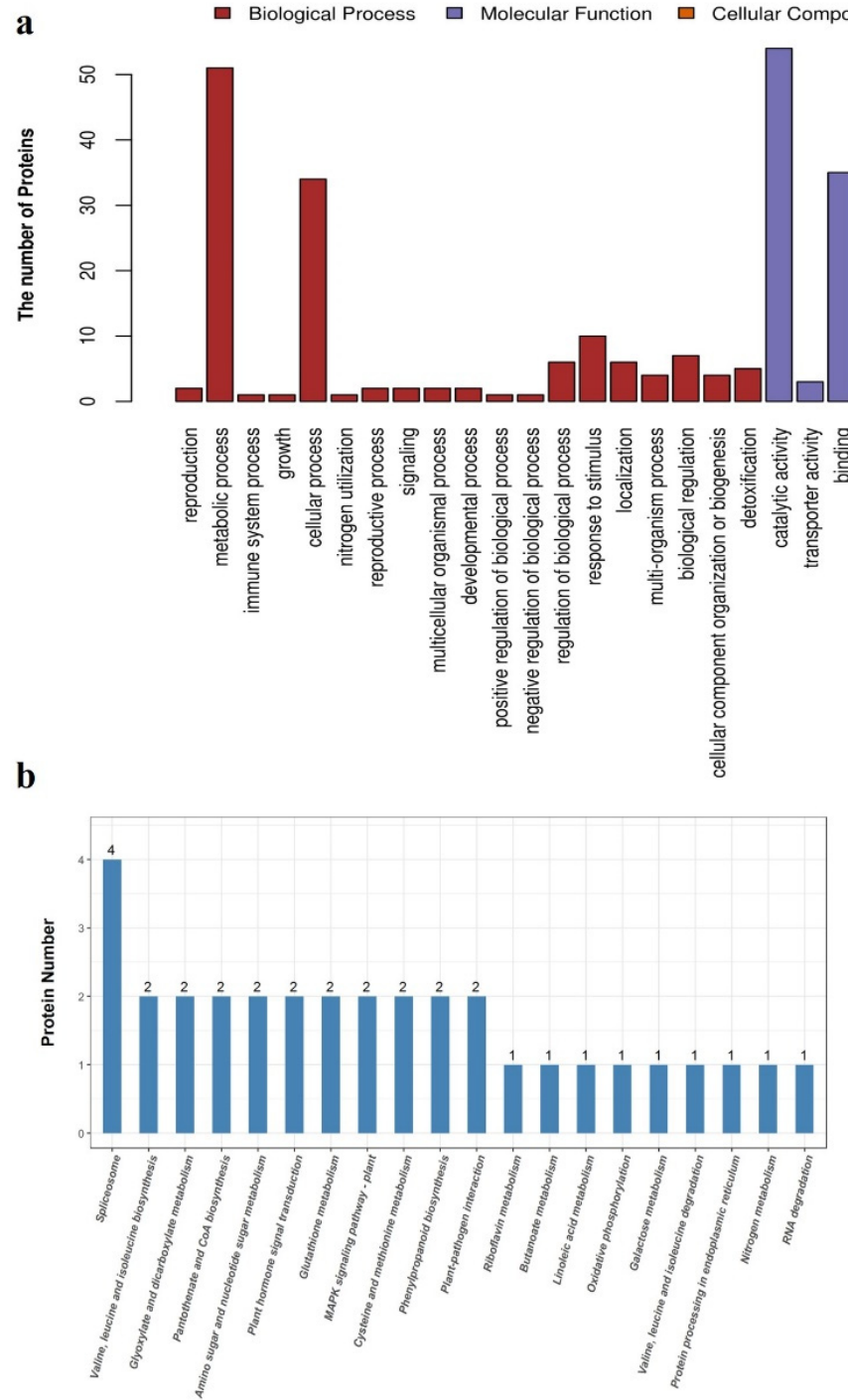

c
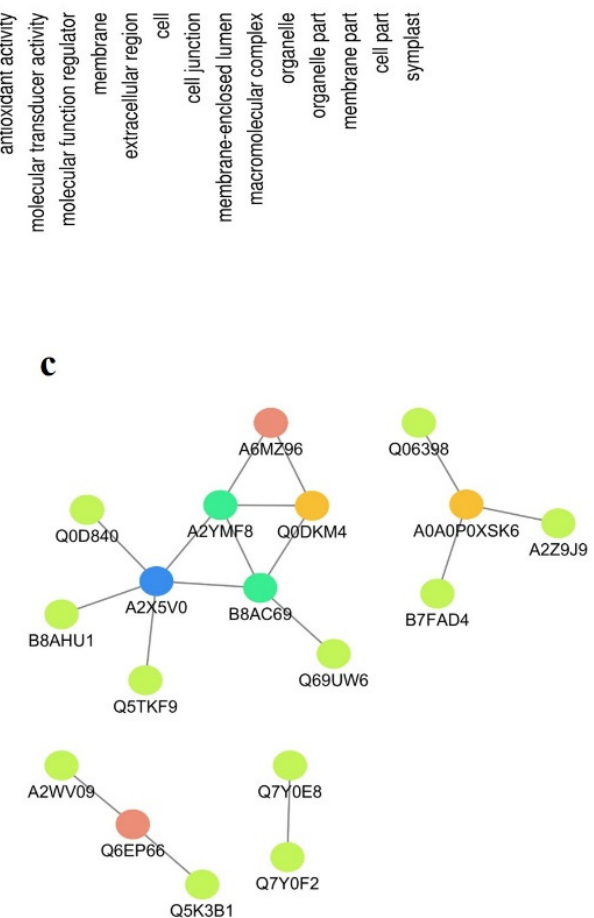

Figure 2. Analysis of identified proteins significantly different between the RCK and RLP samples. (a) Gene Ontology (GO) annotation of the proteins significantly different between the RCK and RLP samples. (b) The top 20 KEGG pathway assignments of the proteins significantly different between the RCK and RLP. The represented categories $(Q \leq 0.05)$ and the number of proteins predicted to belong to each category are shown. (c) The protein-protein interactions (PPI) between the identified proteins. The sphere represents the protein, and the straight line represents the interaction between the proteins at both ends of the straight line.

\subsection{Protein-Protein Interaction (PPI) between the Low-P Responsive Proteins}

Protein is an important component of biological organisms, which do not perform biological function independently, but through the interaction of proteins to regulate physiological and biochemical processes. Therefore, we performed a PPI analysis of the proteins identified by label-free quantitative analysis. As shown (Figure 2c), there was interaction only between a few proteins after screening.

A2X5V0 (Uniprot ID, LOC_Os02g33850, up-regulated) with the function of elongation factor Tu family protein (EF-TU) has five mutual proteins, including Q0D840 
(LOC_Os07g08840, up-regulated) with annotation of thioredoxin, A2YMF8 (LOC_Os07g36490, up-regulated) with annotation of RNA recognition, Q5TKF9 (LOC_Os05g51650, up-regulated) with annotation of U6 snRNA-associated Sm-like protein LSm8, B8AHU1 (LOC_Os02g05880, downregulated) with annotation of RNA polymerase, and B8AC69 (LOC_Os01g16010, downregulated) with annotation of BACS2 protein, which is the core component of the Prp19-related complex, along with being involved in important life activities such as splicing of precursor RNA.

Additionally, B8AC69 and A2YMF8 both have four mutual proteins. Additionally, Q0DKM4 (LOC_Os05g06280, up-regulated) with annotation of U1 small nuclear ribonucleoprotein A and A0A0P0XSK6 (LOC_Os10g07229, up-regulated) with annotation of dehydrogenase have three mutual proteins, respectively. Q6EP66 (LOC_Os09g08660, up-regulated) with annotation of phosphoglycolate phosphatase and A6MZ96 (LOC_Os01g06290, downregulated) with annotation of splicing factor have two mutual proteins, respectively. These results suggested that low $\mathrm{P}$ stress induced reduction of transcription-related genes, and the increase of most RNA splicing related genes along with intensification of the gene expression associated with the elongation during translation.

\subsection{Analysis of Differentially Expressed Proteins Responded to P-Deficiency in DXWR}

In the present study, among 75 SDEPs, there were 24 proteins with fold changes larger than 1.5 both in proteomics and transcriptome level [26] that were associated with P-deficiency treatment in DXWR (Table 3). In addition, we also verified its expression at the transcriptome level by qRT-PCR, which showed consistency in transcriptome data and qRT-PCR results, shown in Figure 3. Among these proteins, 21 up-regulated and two downregulated at both transcriptome and proteome level, and only one had the opposite abundance trend (up-regulated in proteome level but downregulated in transcriptome level). There were some genes whose expression abundance increased in both protein and transcription levels, including OsPT2 (LOC_Os03g05640), OsPT8 (LOC_Os10g30790), OsPAP10c (LOC_Os12g44020), OsPAP10a (LOC_Os01g56880), OsPHF1 (LOC_Os07g09000), as well as a gene encoding glycerophosphoryl diester phosphodiesterase family protein (GDPD, LOC_Os03g40670), three genes encoding glycosyl hydrolase (LOC_Os07g23850, LOC_Os05g15770 and LOC_Os01g47070), and one gene encoding glucan endo-1,3-betaglucosidase precursor (LOC_Os07g35560). Furthermore, a gene (LOC_Os10g35500) encoding epoxide hydrolase increased by low $\mathrm{P}$ stress at proteomic level, but the corresponding transcription levels decreased. The above results indicated that after low P stress treatment, there would be differences in the trend and degree of change in gene expression at the transcription and translation levels.

Table 3. Significant differential expression proteins $(p \leq 0.05)$ with fold changes both in transcriptome and proteomics level larger than 1.5.

\begin{tabular}{|c|c|c|c|c|c|c|}
\hline RAP (Os ID) & MSU (LOC_Os ID) & $\begin{array}{l}\text { RLP/RCK in } \\
\text { Transcriptome }\end{array}$ & $\begin{array}{l}\text { RLP/RCK in } \\
\text { Proteomic }\end{array}$ & $p$ Value & Protein IDs & Annotation \\
\hline Os03g0603600 & LOC_Os03g40670 & 3.572344 & 16.03 & 0.006552 & Q6AUZ6 & $\begin{array}{l}\text { Glycerophosphoryl diester } \\
\text { phosphodiesterase family } \\
\text { protein, expressed }\end{array}$ \\
\hline Os03g0150800 & LOC_Os03g05640 & 4.470767 & 3.96089 & 0.033385 & Q8GSD9 & $\begin{array}{l}\text { Low-affinity transporter for } \\
\text { inorganic phosphate }(\mathrm{Pi})\end{array}$ \\
\hline Os01g0776600 & LOC_Os01g56880 & 1.57171 & 3.622714 & 0.02748 & A0A0P0V8Z3 & Purple acid phosphatase \\
\hline Os10g0444700 & LOC_Os10g30790 & 2.315579 & 3.188358 & 0.000168 & Q8H6G8 & $\begin{array}{l}\text { Probable inorganic } \\
\text { phosphate transporter } 1-8\end{array}$ \\
\hline Os12g0637100 & LOC_Os12g44020 & 2.109139 & 3.158118 & 0.001597 & Q2QLL9 & Purple acid phosphatase \\
\hline Os01g0660200 & LOC_Os01g47070 & 4.556587 & 2.640671 & 0.030145 & A2ZW76 & Glycosyl hydrolase \\
\hline Os12g0198000 & LOC_Os12g09620 & 2.500715 & 2.624379 & $9.82 \mathrm{E}-05$ & Q2QWE5 & Expressed protein \\
\hline Os08g0434100 & LOC_Os08g33710 & 1.591087 & 2.61472 & 0.002771 & Q9FRU0 & Ribonuclease \\
\hline Os07g0129200 & LOC_Os07g03710 & 1.872105 & 2.294623 & 0.001414 & B9FVB5 & $\begin{array}{l}\text { SCP-like extracellular } \\
\text { protein, expressed }\end{array}$ \\
\hline
\end{tabular}


Table 3. Cont.

\begin{tabular}{|c|c|c|c|c|c|c|}
\hline RAP (Os ID) & MSU (LOC_Os ID) & $\begin{array}{l}\text { RLP/RCK in } \\
\text { Transcriptome }\end{array}$ & $\begin{array}{l}\text { RLP/RCK in } \\
\text { Proteomic }\end{array}$ & $p$ Value & Protein IDs & Annotation \\
\hline Os05g0402900 & LOC_Os05g33400 & 3.22764 & 2.229987 & 0.045047 & B9FPI6 & $\begin{array}{c}\text { Basic } 7 \mathrm{~S} \text { globulin precursor, } \\
\text { putative, expressed } \\
\text { Ribonuclease T2 family }\end{array}$ \\
\hline Os07g0630400 & LOC_Os07g43670 & 1.90585 & 2.18514 & 0.004417 & Q8H4E4 & $\begin{array}{c}\text { domain containing protein, } \\
\text { expressed }\end{array}$ \\
\hline Os10g0538200 & LOC_Os10g39300 & 7.334062 & 2.147759 & 0.030829 & A2Z9R9 & $\begin{array}{l}\text { Aspartic proteinase } \\
\text { nepenthesin, putative, } \\
\text { expressed }\end{array}$ \\
\hline Os01g0357100 & LOC_Os01g25484 & 2.89252 & 2.139517 & 0.015234 & B8A7W8 & $\begin{array}{l}\text { Ferredoxin-nitrite } \\
\text { reductase, putative, } \\
\text { expressed }\end{array}$ \\
\hline Os10g0191300 & LOC_Os10g11500 & 1.800917 & 2.010712 & 0.0018 & Q8LMW8 & $\begin{array}{l}\text { SCP-like extracellular } \\
\text { protein, expressed }\end{array}$ \\
\hline Os05g0247100 & LOC_Os05g15770 & 4.70642 & 2.004889 & 0.03089 & Q5WMX0 & $\begin{array}{l}\text { Similar to glycosyl } \\
\text { hydrolases Family } 18\end{array}$ \\
\hline NONE & LOC_Os07g23850 & 1.549946 & 1.977236 & 0.016379 & $\mathrm{~A} 2 \mathrm{YKM} 4$ & $\begin{array}{l}\text { Glycosyl hydrolase } \\
\text { Glucan }\end{array}$ \\
\hline Os07g0539900 & LOC_Os07g35560 & 2.59231 & 1.773463 & 0.027652 & B9FXQ1 & $\begin{array}{c}\text { endo-1,3-beta-glucosidase } \\
\text { precursor, putative, } \\
\text { expressed }\end{array}$ \\
\hline Os01g0687400 & LOC_Os01g49320 & 1.944762 & 1.760767 & 0.04272 & Q7XXQ0 & Chitinase \\
\hline & & & & & & $\begin{array}{l}\text { WD40 protein, regulation of } \\
\text { the plasma membrane }\end{array}$ \\
\hline Os07g0187700 & LOC_Os07g09000 & 1.874014 & 1.663966 & 0.037637 & Q6Z4F3 & $\begin{array}{l}\text { localization of phosphate } \\
\text { transporters, Phosphate } \\
\text { uptake and translocation }\end{array}$ \\
\hline Os01g0132000 & LOC_Os01g04050 & 1.955063 & 1.654255 & 0.017942 & Q9LGB2 & $\begin{array}{l}\text { BBTI12 - Bowman-Birk type } \\
\text { bran trypsin inhibitor } \\
\text { precursor, expressed }\end{array}$ \\
\hline Os10g0498100 & LOC_Os10g35500 & 0.314414 & 1.592639 & 0.014471 & АЗС 655 & Epoxide hydrolase \\
\hline Os07g0638100 & LOC_Os07g44410 & 1.589194 & 1.55019 & 0.002186 & Q8GVH2 & $\begin{array}{l}\text { WD40-like Beta propeller } \\
\text { repeat family protein }\end{array}$ \\
\hline Os08g0374000 & LOC_Os08g28670 & 0.489589 & 0.636557 & 0.001251 & Q6ZD29 & $\begin{array}{l}\text { Bet v I allergen family } \\
\text { protein OsBet v I }\end{array}$ \\
\hline Os02g0620500 & LOC_Os02g40710 & 0.635764 & 0.473226 & 0.039294 & Q6K9G3 & $\begin{array}{l}\text { Ammonium transporter } 1 \\
\text { member } 3\end{array}$ \\
\hline
\end{tabular}

3.6. Conjoint Analysis of Proteomic and QTLs Related to P-Deficiency Tolerance

As shown in Table 4, there are two P-deficiency tolerance related QTLs have been identified in DXWR [23], and 12 QTLs existing in different positions on the chromosome related to P-deficiency stress have been found in Oryza sativa based on the Gramene QTL database. Among genes corresponding to 75 SDEPs identified by the proteome in this study, we located nine genes among these QTL intervals, as shown in Table 5. Among them, two genes (LOC_Os12g44020, OsPAP10c and LOC_Os04g41970, OsGLU3) have been characterized in previous studies [36,37], and two of the other seven uncharacterized genes (LOC_Os12g09620 and LOC_Os03g40670) have been detected at both transcriptome and proteome levels. Furthermore, the functional expression characteristics of the remaining five genes (LOC_Os01g57450,LOC_Os03g29240,LOC_Os03g13540,LOC_Os03g29190 and LOC_Os06g07600) have not been reported yet. 
Table 4. Previously identified P-deficiency responses related to QTL intervals.

\begin{tabular}{cccc}
\hline QTL ID & Species Name & Chromosome & Position \\
\hline AQBD004 & Oryza sativa & 1 & $41,967,890-41,969,197 \mathrm{bp}$ \\
AQCI001 & Oryza sativa & 2 & $8,984,645-18,496,476 \mathrm{bp}$ \\
AQCI008 & Oryza sativa & 3 & $6,753,341-10,322,897 \mathrm{bp}$ \\
AQCI006 & Oryza sativa & 4 & $88,362-4,439,573 \mathrm{bp}$ \\
AQCI011 & Oryza sativa & 4 & $24,690,120-27,908,404 \mathrm{bp}$ \\
AQCI002 & Oryza sativa & 6 & $3,536,009-4,952,592 \mathrm{bp}$ \\
AQCI009 & Oryza sativa & 6 & $1,644,474-4,952,592 \mathrm{bp}$ \\
AQCI003 & Oryza sativa & 10 & $7,639,733-14,271,753 \mathrm{bp}$ \\
AQBD007 & Oryza sativa & 12 & $1,548,040-1,548,464 \mathrm{bp}$ \\
AQCI012 & Oryza sativa & 12 & $3,885,926-27,489,485 \mathrm{bp}$ \\
AQCI013 & Oryza sativa & 12 & $1,548,040-18,867,702 \mathrm{bp}$ \\
AQAZ001 & Oryza sativa & 12 & $13,101,084-15,120,848 \mathrm{bp}$ \\
qMLR-1 & DXWR & 1 & $33,053,493-36,734,272 \mathrm{bp}$ \\
qTDW-2 & DXWR & 3 & $12,407,382-23,822,102 \mathrm{bp}$ \\
\hline
\end{tabular}

$\mathrm{bp}=$ base pair.

Table 5. Located genes encoded significantly different expression proteins identified from label-free quantitative analysis among previously identified P-deficiency responses related QTL intervals.

\begin{tabular}{|c|c|c|c|c|c|}
\hline RAP (Os ID) & MSU (LOC_Os ID) & $\begin{array}{l}\text { Mapped QTL } \\
\text { Accession ID }\end{array}$ & Description & Ratio (RLP/RCK) & $p$ Value \\
\hline Os01g0783500 & LOC_Os01g57450 & qMLR-1 & $\begin{array}{l}\text { Universal stress protein domain } \\
\text { containing protein }\end{array}$ & 1.52646 & 0.005096 \\
\hline Os03g0603600 & LOC_Os03g40670 & qTDW-2 & $\begin{array}{c}\text { Glycerophosphoryl diester } \\
\text { phosphodiesterase } \\
\text { family protein }\end{array}$ & 16.03 & 0.006552 \\
\hline Os03g0405900 & LOC_Os03g29240 & qTDW-2 & Probable nucleoredoxin 1-2 & 2.22151 & 0.0006 \\
\hline Os03g0238600 & LOC_Os03g13540 & AQCI008 & Purple acid phosphatase & 1.95551 & 0.0009 \\
\hline Os03g0405500 & LOC_Os03g29190 & qTDW-2 & Probable nucleoredoxin 1-1 & 1.82238 & 0.017644 \\
\hline Os06g0172800 & LOC_Os06g07600 & $\begin{array}{l}\text { AQCI002, } \\
\text { AQCI009 }\end{array}$ & $\begin{array}{l}\text { Uncharacterized } \\
\text { glycosyltransferase }\end{array}$ & 1.87172 & 0.010126 \\
\hline Os12g0637100 & LOC_Os12g44020 & AQCI012 & Purple acid phosphatase & 3.15812 & 0.001597 \\
\hline Os12g0198000 & LOC_Os12g09620 & $\begin{array}{l}\text { AQCCI012, } \\
\text { AQCI013 }\end{array}$ & Expressed protein & 2.62438 & $9.82 \times 10^{-5}$ \\
\hline Os04g0497200 & LOC_Os04g41970 & AQCI011 & Endoglucanase 12 & 0.41442 & 0.019558331 \\
\hline
\end{tabular}

\subsection{The Expression Pattern of Genes Related to P-Deficiency Tolerance in DXWR}

Based on previous studies on P-response mechanism in cultivated rice, the homologous genes of PHR1 (OsPHR2 and OsPHR1), OsPHO2, OsPHO1, as well as its NATs, play an important role in the low P-response process $[7,38]$. Therefore, we examined the expression levels of OsPHR2 and OsPHO2 as well as three members of OsPHO1 (OsPHO1;1, OsPHO1;2 and OsPHO1;3) and three NATs correspondently, as shown in Figure 4. We found that OsPHR2 was downregulated after low P treatment in DXWR roots, which was contrary to the results of previous studies on cultivated rice $[7,38]$. We suspect that OsPHR1 may play a major role during the $P$ starvation signaling pathway in DXWR. For validation, we examined the expression of OsPHR1 in DXWR, but the result was consistent with OsPHR2 and also down-regulated. Such results may indicate that the transcription levels of OsPHR1 and OsPHR2 are inhibited by low P signals in DXWR. In addition, OsPHO2 was downregulated in both DXWR and NP. Among OsPHO1;1, OsPHO1;2, and OsPHO1;3, only OsPHO1;3 expression was up-regulated and the other two were downregulated in DXWR, but three genes all up-regulated in NP. In the corresponding NAT, only OsPHO1;2 NAT expression change trend is consistent with OsPHO1;2, and the other two NATs change trend is opposite to OsPHO1;1 and OsPHO1;3 in DXWR. However, all three NATs up-regulated in NP. These results indicate that there may be a difference in the mechanism of resistance to low P in DXWR compared to cultivated rice. 

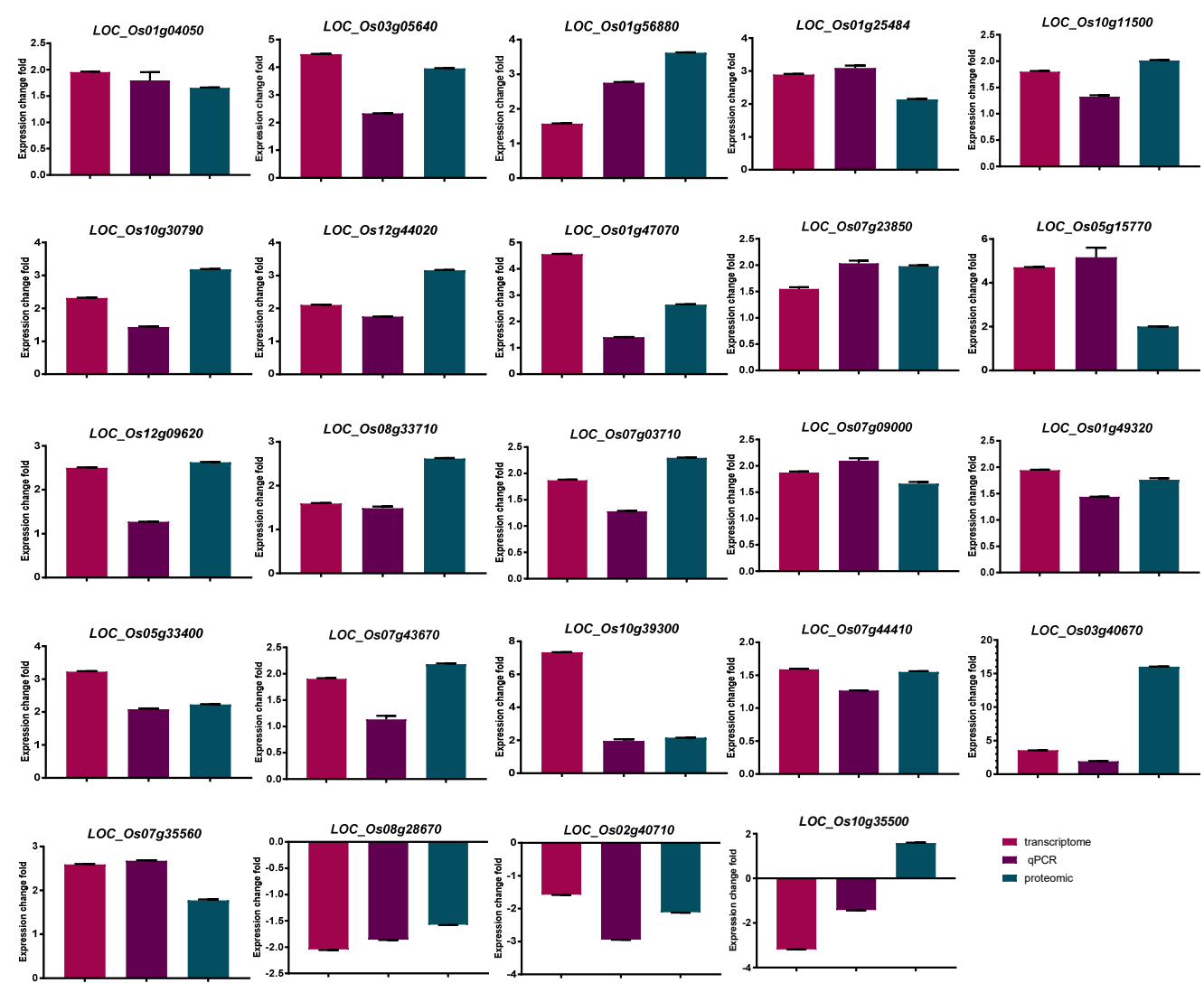

Figure 3. Quantitative real-time PCR analysis of 24 significant differential expression proteins with fold changes both in transcriptome and proteomics levels larger than 1.5 in DXWR. Bars mean SD. Expression change fold refers to the change of the treatment group compared with the control group.
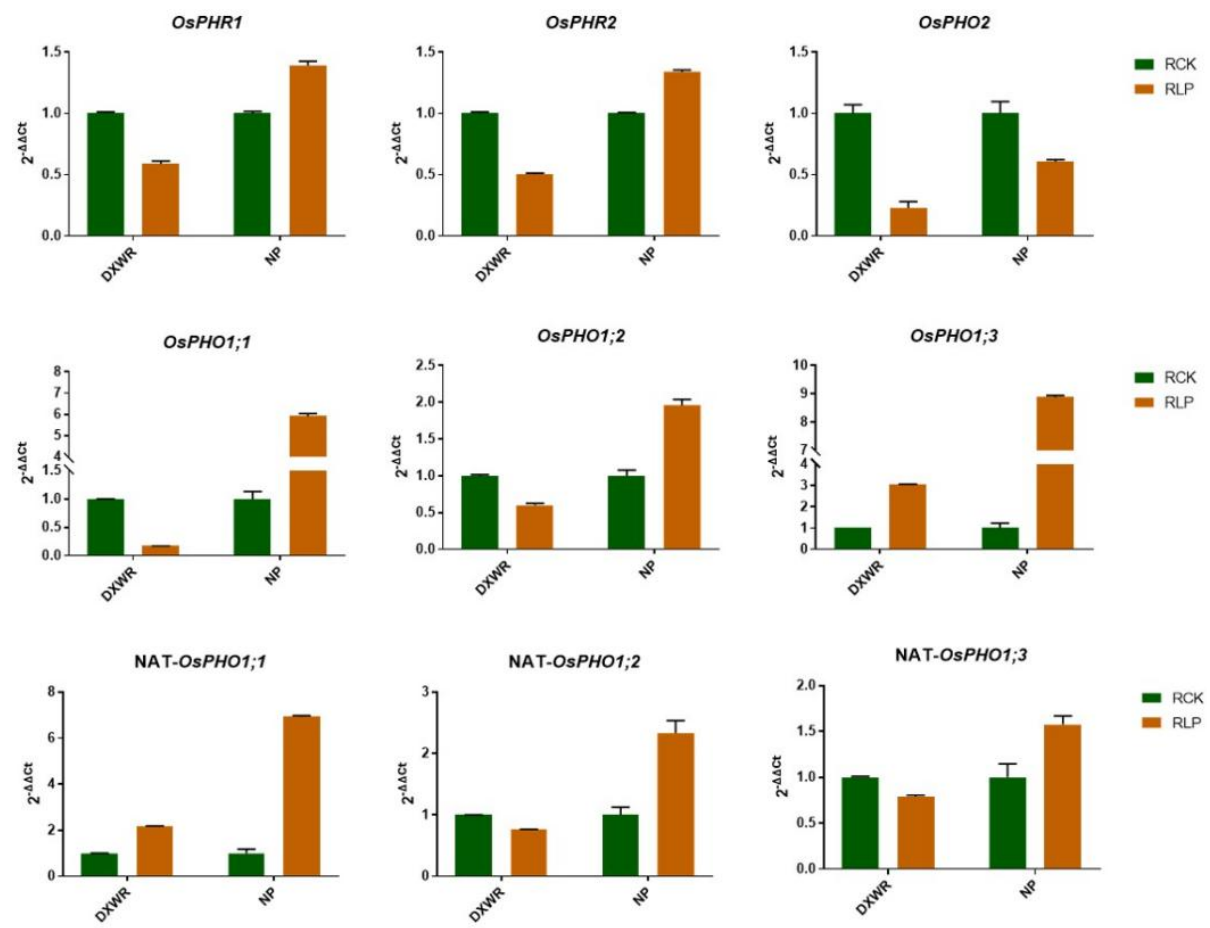

Figure 4. Expression pattern in DXWR and NP of key genes that characterized in cultivated rice participating in the P-regulation network detected by qRT-PCR. Error bar means standard deviation. 


\section{Discussion}

\subsection{Low P Stress Leads to Differential Expression of P Absorption Efficiency Related Genes in DXWR}

A previous study [39] has shown that OsPHF1 regulates the plasma membrane localization of low-affinity Pi transporter OsPT2 and the high-affinity Pi transporter OsPT8, of which ortholog in Arabidopsis reported to be only an important factor for the localization of high-affinity Pi transporters to the plasma membrane [40]. Subcellular location experiments show that mutation of OsPHF1 lead to the retention of OsPT2 and OsPT8 in the endoplasmic reticulum and reduce the accumulation of $\mathrm{Pi}$ in shoots due to overexpression of OsPHR2 $[39,41]$. To the contrary, overexpression of OsPHF1 results in excessive Pi accumulation in leaf and root. Furthermore, OSPT2 is the only low affinity transporter in the PHT1 family induced by Pi deprivation under the transcriptional control of OsPHR2, whereas OsPT8 is constitutively expressed high-affinity Pi transporters in rice whose expression is not affected by external Pi levels. In our study, the expression levels of OsPT2 (LOC_Os03g05640), OsPT8 (LOC_Os10g30790) and OsPHF1 (LOC_Os07g09000) were upregulated. The up-regulated expression of OsPHF1 may increase the plasma membrane localization of OsPT2 and OsPT8.

On the other hand, purple acid phosphatase (PAP) is a family of metals phosphoesterases involved in a variety of physiological functions, especially in low Pi adaptations in plants [42]. PAPs have non-specific acidic phosphatase activity, which can catalyze the hydrolysis of various organic $\mathrm{P}$ into Pi under acidic $\mathrm{pH}$ conditions, thus providing more Pi for plants $[36,43]$. PAP plays a critical role in the plant's ability to utilize organic $P$ in growth medium. There were two PAP genes, OsPAP10c (LOC_Os12g44020) and OsPAP10a (LOC_Os01g56880) induced by low P stress in DXWR. It is likely that they play a crucial role in the ability of plants to use organic $\mathrm{P}$.

In addition to the above-mentioned genes that may increase the efficiency of $\mathrm{P}$ absorption of DXWR, there are other functional genes that are differentially expressed. Studies have shown that PGP inactivation attenuated triosephosphate isomerase activity, thereby increasing triglyceride levels at the expense of the cellular phosphatidylcholine content, and inhibiting cell proliferation $[44,45]$. These effects were prevented under hypoxic conditions or by blocking phosphoglycolate release from damaged DNA. Moreover, as shown, EF-TU plays an important role in the reproduction, development, and response to environmental stress of higher plants [46]. Here, the increased synthesis of PGP (LOC_Os09g08660) and EF-TU (LOC_Os02g33850) may be the response of DXWR to low P stress. Furthermore, chitinase leads to the separation of parallel chitin microfibrils connected by $\beta-1,6$-branched chain $\beta-1,3-$ glucans in the cell wall, thus increasing the interval between the insertion of newly synthesized chitin and $\beta-1,3-$ glucans under swelling in vivo [47]. In this study, it was worth noting that the expression of chitinase (LOC_Os01g49320) and glycosyl hydrolase (LOC_Os01g47070) increased when the root of DXWR was under low P stress. The differential expression of these genes may imply a strategy for DXWR to respond to low $\mathrm{P}$ stress by improving $\mathrm{P}$ absorption efficiency.

\subsection{Differential Expression of Variable Splicing-Related Genes May Contribute to the Low P Resistance for DXWR}

Studies have shown that the absence of SR or SPF protein can lead to changes in splice sites $[48,49]$. LSm8 is essential for the assembly of the LSM nuclear complex (LSm2-8) and this complex acts in pre-mRNA splicing through U6 snRNA stabilization, thus allowing the formation of the U6 snRNP [50]. The Arabidopsis LSM2-8 complex differentially regulates plant tolerance to abiotic stresses by controlling the constitutive and alternative splicing of specific introns from selected abiotic stress-related pre-mRNAs [51]. In this study, the up-regulation of LSm8 (LOC_Os05g51650) and U1A (LOC_Os05g06280) may alternate splicing of pre-mRNA, while the down-regulation of SPF (LOC_Os01g16010) and SR (LOC_Os01g06290) may change the pre-mRNA splicing site, thus contributing to low $\mathrm{P}$ resistance of DXWR. 


\subsection{Increase the Antioxidant Capacity of DXWR by Regulating the Expression of Related Genes}

Studies have shown that plants under abiotic stress are coerced to increase the activity of reactive oxygen species (ROS) and antioxidant enzymes [52,53]. As shown, a key enzyme in the BCAAs biosynthesis pathway, ALS, was downregulated under stress [52]. In addition, by increasing the concentration of BCAAs to $100 \mathrm{mg} / \mathrm{L}$ in the culture medium, ROS was significantly reduced, thereby reducing the level of antioxidant enzymes in herbicide-stressed plants [53]. In present research, DXWR may enhance the biosynthesis of BCAAs through up-regulating BCAT (LOC_Os03g01600) and ALS (LOC_Os11g14950) to reduce ROS and consequently antioxidant enzyme levels. What's more, Glutathione is a co-substrate for glutathione-S-transferase (GST), which in rice participates in various functions such as phytohormone homeostasis, hydroxy peroxide detoxification, apoptosis regulation [54], and also has a key role in response to biotic and abiotic stresses [55]. In this study, two GST proteins (LOC_Os10g38740 and LOC_Os10g38360) enriched in glutathione metabolism pathway were up-regulated after P-deficiency treatment of DXWR which might increase the tolerance to cope with low P stress. Furthermore, epoxide hydrolase has been reported as an enzyme that reduces the content of epoxides in organisms by means of chemically catalyzed transformation, as well as metabolizes endogenous aliphatic and aromatic epoxides [56]. It is a key enzyme involved in metabolism, detoxification, and signaling regulation in the organism [57]. In this study, an epoxide hydrolase protein (LOC_Os10g35500) increased in protein level might increase the tolerance to low P stress, but the corresponding transcription level decreased, possibly by increasing the stability of the corresponding mRNA and reducing the number of transcriptions to reduce energy consumption.

\subsection{DXWR May Exist a Low P Tolerance Mechanism Different from Cultivated Rice NP}

PHR1 is a central regulator of P-deficiency stress response [6]. There are two homologous genes of PHR1 in rice, namely OsPHR1 and OsPHR2. Some studies have shown that OsPHR2 plays a major role in the P starvation signaling pathway that is induced by low phosphorus stress. [7,38]. However, in this study, both OsPHR2 and OsPHR1 were downregulated after receiving low P stress in DXWR, which was opposite to that in NP. After Pi enters the column cells of the root, PHO1 located in the xylem of the root vascular bundle is responsible for loading Pi into the xylem and then transporting it from the xylem to the shoot [58,59]. In Arabidopsis, mainly AtPHO1 and AtPHO1;H1 are involved in the P transportation from root to shoot [60]. There are three homologous genes of AtPHO1 and AtPHO1;H1 in rice, which are OsPHO1;1, OsPHO1;2, and OsPHO1; 3, and all three genes have NAT at the $5^{\prime}$ end [38]. Studies among cultivated rice showed that OsPHO1;2 played a main role in the transport and distribution of $\mathrm{P}$, while OsPHO1;2 NAT was induced by P starvation and could activate the expression of OsPHO1;2 [38], which was consistent with our results in NP. However, in DXWR, OsPHO1;2 and its NAT both downregulated by low P stress, whereas OsPHO1;1 downregulated and its NAT up-regulated, as well as $\mathrm{OsPHO} ; 3$ up-regulated and its NAT downregulated. In addition, OsPHO2 containing a E2 ubiquitin-binding domain could degrade OsPHO1 [61], of which the downregulated expression results consistent with previous studies were obtained in both DXWR and NP. Through the above analysis, we found that OsPHR1 OsPHR2, three OsPHO1, and the corresponding NATs showed different response trends in DXWR and NP, except for OsPHO2. These differences indicate that DXWR may have a unique resistance to low $\mathrm{P}$ regulation, and these candidate genes screened by transcriptome and proteome in the present study may also have unique functions in DXWR different from cultivated rice.

\section{Conclusions}

In this study, label-free proteomics analysis as well as joint analysis with transcriptome dataset were conducted to root samples to identify potential unique low P-response genes in DXWR during seedlings. 75 SDEPs were detected, 24 of which were also detected in previous transcriptome dataset verified by qRT-PCR. Furthermore, it was found that DXWR could increase PAPs' expression, membrane location of PTs, rhizosphere area, alternative 
splicing and decrease ROS activity to deal with low P stress. Moreover, among the genes corresponding to 75 SDEPs, seven uncharacterized genes were located in previous P related QTL intervals, of which two genes (LOC_Os12g09620 and LOC_Os03g40670) have been detected at both transcriptome and proteome levels. In addition, the expression patterns of OsPHR1, OsPHR2, OsPHO1, and NAT-OsPHO1 in DXWR were different in cultivated rice $\mathrm{NP}$, suggesting that the response mechanism of some low $\mathrm{P}$ tolerance in DXWR might be different from that in cultivated rice. These findings would provide insights in cloning the $\mathrm{P}$-deficiency genes from wild rice, as well as elucidating the molecular mechanism of low $\mathrm{P}$ resistance in DXWR.

Supplementary Materials: The following are available online at https:/ / www.mdpi.com/article/ 10.3390/genes13010108/s1, Supplementary Table S1: Primer used for qRT-PCR analysis. Supplementary Figure S1: Molecular weight distribution. Supplementary Table S2: List of proteins identified from RLP and RCK samples with three biological repetitions, respectively. Supplementary Table S3: List of peptides identified from RLP and RCK samples with three biological repetitions, respectively. Supplementary Table S4: List of GO function enrichment analysis of proteins identified from RLP and RCK. Supplementary Table S5: List of KEGG pathway mapping of proteins identified from RLP and RCK.

Author Contributions: Conceptualization, Q.D., J.X. and X.L.; methodology, Q.D., L.D. and Y.C.; software, Q.D., D.W. and Y.S.; validation, Q.D., D.W. and Y.S.; writing-original draft preparation, Q.D., L.D.; writing - review and editing, Q.D., Y.C.; supervision, J.X. and X.L. All authors have read and agreed to the published version of the manuscript.

Funding: This research was partially supported by the National Natural Science Foundation of China (32060074 and 31660384), the Key Project of Natural Science Foundation of Jiangxi Province, China [20202ACB205001]; Major Academic and Technical Leader Training Project of Jiangxi Province [20204BCJ22024].

Institutional Review Board Statement: Not applicable.

Informed Consent Statement: Not applicable.

Data Availability Statement: Data is contained within the article and Supplementary Material.

Acknowledgments: We thank Researcher Jun Fang of the Northeast Institute of Geography and Agroecology, Chinese Academy of Sciences, for providing the experimental platform. Thanks Shanghai Applied Protein Technology (Shanghai, China) provided help for LC-MS/MS analysis.

Conflicts of Interest: The authors declare no conflict of interest.

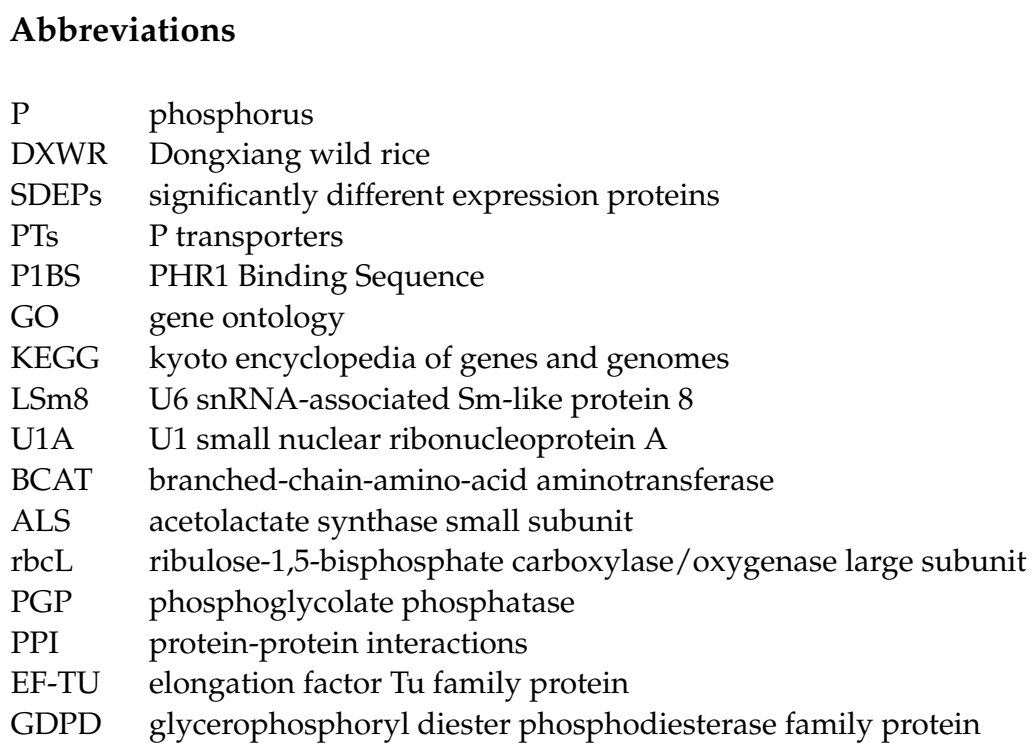


PAP purple acid phosphatases;

GST glutathione-S-transferase

PHR1 phosphate starvation response regulator 1

qRT-PCR quantitative real-time PCR

\section{References}

1. Zhang, H.; Zhang, F.W.; He, Z.; He, L.X.; Zeng, Y.W.; Lei, S.X. Progress in research of tolerance to low-phosphorus in rice. J. Yunnan Agric. Univ. 2009, 24, 754-758.

2. Wang, R.C.; Cheng, S.H.; Cao, L.Y. Advancements in phosphorus deficiency tolerance study in rice (Oryza sativa L.). Chin. Agric. Sci. Bull. 2009, 25, 77-83.

3. Cordell, D.; Drangert, J.O.; White, S. The story of phosphorus: Global food security and food for thought. Glob. Environ. Chang. 2009, 19, 292-305. [CrossRef]

4. Vance, C.P.; Uhde-Stone, C.; Allan, D.L. Phosphorus acquisition and use: Critical adaptations by plants for securing a nonrenewable resource. New Phytol. 2003, 157, 423-447. [CrossRef]

5. Bernardino, K.C.; Pastina, M.M.; Menezes, C.B.; de Sousa, S.M.; Maciel, L.S.; Carvalho, G.J.; Guimarães, C.T.; Barros, B.A.; da Costa, E.; Silva, L.; et al. The genetic architecture of phosphorus efficiency in sorghum involves pleiotropic QTL for root morphology and grain yield under low phosphorus availability in the soil. BMC Plant Biol. 2019, 19, 87. [CrossRef]

6. Rubio, V.; Linhares, F.; Solano, R.; Martín, A.C.; Iglesias, J.; Leyva, A.; Paz-Ares, J. A conserved MYB transcription factor involved in phosphate starvation signaling both in vascular plants and in unicellular algae. Genes Dev. 2001, 15, 2122-2133. [CrossRef]

7. Zhou, J.; Jiao, F.; Wu, Z.; Li, Y.; Wang, X.; He, X.; Zhong, W.; Wu, P. OsPHR2 is involved in phosphate-starvation signaling and excessive phosphate accumulation in shoots of plants. Plant Physiol. 2008, 146, 1673-1686. [CrossRef]

8. Bustos, R.; Castrillo, G.; Linhares, F.; Puga, M.I.; Rubio, V.; Pérez-Pérez, J.; Solano, R.; Leyva, A.; Paz-Ares, J. A central regulatory system largely controls transcriptional activation and repression responses to phosphate starvation in Arabidopsis. PLoS Genet. 2010, 6, e1001102. [CrossRef]

9. Ruan, W.; Guo, M.; Wu, P.; Yi, K. Phosphate starvation induced OsPHR4 mediates Pi-signaling and homeostasis in rice. Plant Mol. Biol. 2017, 93, 327-340. [CrossRef]

10. Ai, P.; Sun, S.; Zhao, J.; Fan, X.; Xin, W.; Guo, Q.; Yu, L.; Shen, Q.; Wu, P.; Miller, A.J.; et al. Two rice phosphate transporters, OsPHT1;2 and OsPHT1;6, have different functions and kinetic properties in uptake and translocation. Plant J. Cell Mol. Biol. 2009, 57, 798-809. [CrossRef]

11. Wang, X.; Wang, Y.; Piñeros, M.A.; Wang, Z.; Wang, W.; Li, C.; Wu, Z.; Kochian, L.V.; Wu, P. Phosphate transporters OsPHT1;9 and OsPHT1;10 are involved in phosphate uptake in rice. Plant Cell Environ. 2014, 37, 1159-1170. [CrossRef]

12. Chang, M.X.; Gu, M.; Xia, Y.W.; Dai, X.L.; Dai, C.R.; Zhang, J.; Wang, S.C.; Qu, H.Y.; Yamaji, N.; Ma, J.F.; et al. OsPHT1;3 mediates uptake, translocation and remobilization of phosphate under extremely low phosphate regimes. Plant Physiol. 2018, 179, 656-670. [CrossRef]

13. Yang, S.Y.; Grønlund, M.; Jakobsen, I.; Grotemeyer, M.S.; Rentsch, D.; Miyao, A.; Hirochika, H.; Kumar, C.S.; Sundaresan, V.; Salamin, N.; et al. Nonredundant regulation of rice arbuscular mycorrhizal symbiosis by two members of the phosphate transporter1 gene family. Plant Cell 2012, 24, 4236-4251. [CrossRef]

14. Li, J.Z.; Xie, Y.; Dai, A.Y.; Liu, L.F.; Li, Z.C. Root and shoot traits responses to phosphorus deficiency and QTL analysis at seedling stage using introgression lines of rice. J. Genet. Genom. 2009, 36, 173-183. [CrossRef]

15. Chin, J.H.; Lu, X.; Haefele, S.M.; Gamuyao, R.; Ismail, A.; Wissuwa, M.; Heuer, S. Development and application of gene-based markers for the major rice QTL Phosphorus uptake 1. Theor. Appl. Genet. 2010, 120, 1073-1086. [CrossRef]

16. Mukherjee, A.; Sarkar, S.; Chakraborty, A.S.; Yelne, R.; Kavishetty, V.; Biswas, T.; Mandal, N.; Bhattacharyya, S. Phosphate acquisition efficiency and phosphate starvation tolerance locus (PSTOL1) in rice. J. Genet. 2014, 93, 683-688. [CrossRef]

17. Wang, W.; Zhang, Y.; Ding, G.; White, P.J.; Broadley, M.R.; Hammond, J.P.; Jin, K.; Cai, H.; Xu, F. Identification of QTLs for relative root traits associated with phosphorus efficiency in two culture systems in Brassica napus. Euphytica 2019, 215, 192. [CrossRef]

18. Wasaki, J.; Yonetani, R.; Shinano, T.; Kai, M.; Osaki, M. Expression of the OsPI1 gene, cloned from rice roots using cDNA microarray, rapidly responds to phosphorus status. New Phytol. 2003, 158, 239-248. [CrossRef]

19. Yi, K.; Wu, Z.; Zhou, J.; Du, L.; Guo, L.; Wu, Y.; Wu, P. OsPTF1, a novel transcription factor involved in tolerance to phosphate starvation in rice. Plant Physiol. 2005, 138, 2087-2096. [CrossRef]

20. Gamuyao, R.; Chin, J.H.; Pariasca-Tanaka, J.; Pesaresi, P.; Catausan, S.; Dalid, C.; Slamet-Loedin, I.; Tecson-Mendoza, E.M.; Wissuwa, M.; Heuer, S. The protein kinase Pstol1 from traditional rice confers tolerance of phosphorus deficiency. Nature 2012, 488, 535-539. [CrossRef]

21. Wissuwa, M.; Kondo, K.; Fukuda, T.; Mori, A.; Rose, M.T.; Pariasca-Tanaka, J.; Kretzschmar, T.; Haefele, S.M.; Rose, T.J. Unmasking Novel Loci for Internal Phosphorus Utilization Efficiency in Rice Germplasm through Genome-Wide Association Analysis. PLoS ONE 2015, 10, e0124215. [CrossRef]

22. Ogawa, S.; Selvaraj, M.G.; Fernando, A.J.; Lorieux, M.; Ishitani, M.; McCouch, S.; Arbelaez, J.D. N- and P-mediated seminal root elongation response in rice seedlings. Plant Soil 2014, 375, 303-315. [CrossRef]

23. Luo, X.D.; Liu, J.; Dai, L.F.; Zhang, F.T.; Wan, Y.; Xie, J.K. Linkage map construction and QTL identification of P-deficiency tolerance in Oryza rufipogon Griff. at early seedling stage. Euphytica 2017, 213, 96. [CrossRef] 
24. Xie, J.; Agrama, H.A.; Kong, D.; Zhuang, J.; Hu, B.; Wan, Y.; Yan, W. Genetic diversity associated with conservation of endangered Dongxiang wild rice (Oryza rufipogon). Genet. Resour. Crop. Evol. 2010, 57, 597-609. [CrossRef]

25. Jian, S.R.; Wan, Y.; Luo, X.D.; Fang, J.; Chu, C.C.; Xie, J.K. Genetic analysis of cold tolerance at the seedling stage in Dongxiang wild rice (Oryza rufipogon). Bull. Bot. 2011, 46, 21-27.

26. Deng, Q.W.; Luo, X.D.; Chen, Y.L.; Zhou, Y.; Zhang, F.T.; Hu, B.L.; Xie, J.K. Transcriptome analysis of phosphorus stress responsiveness in the seedlings of Dongxiang wild rice (Oryza rufipogon Griff.). Biol. Res. 2018, 51, 7. [CrossRef]

27. Yoshida, S.; Forno, D.A.; Cock, J.H.; Gomez, K.A. Laboratory Manual for Physiological Studies of Rice, 3rd ed.; International Rice Research Institute: Manila, Philippines, 1976.

28. Méchin, V.; Damerval, C.; Zivy, M. Total protein extraction with TCA-acetone. Methods Mol. Biol. 2007, 355, 1-8.

29. Cox, J.; Neuhauser, N.; Michalski, A.; Scheltema, R.A.; Olsen, J.V.; Mann, M. Andromeda: A peptide search engine integrated into the MaxQuant environment. J. Proteome Res. 2011, 10, 1794-1805. [CrossRef]

30. Cox, J.; Hein, M.Y.; Luber, C.A.; Paron, I.; Nagaraj, N.; Mann, M. Accurate proteome-wide label-free quantification by delayed normalization and maximal peptide ratio extraction, termed MaxLFQ. Mol. Cell. Proteom. 2014, 13, 2513-2526. [CrossRef]

31. Quevillon, E.; Silventoinen, V.; Pillai, S.; Harte, N.; Mulder, N.; Apweiler, R.; Lopez, R. InterProScan: Protein domains identifier. Nucleic Acids Res. 2005, 33, W116-W120. [CrossRef]

32. Ashburner, M.; Ball, C.A.; Blake, J.A.; Botstein, D.; Butler, H.; Cherry, J.M.; Davis, A.P.; Dolinski, K.; Dwight, S.S.; Eppig, J.T.; et al. Gene ontology: Tool for the unification of biology. The Gene Ontology Consortium. Nat. Genet. 2000, 25, 25-29. [CrossRef]

33. Götz, S.; García-Gómez, J.M.; Terol, J.; Williams, T.D.; Nagaraj, S.H.; Nueda, M.J.; Robles, M.; Talón, M.; Dopazo, J.; Conesa, A. High-throughput functional annotation and data mining with the Blast2GO suite. Nucleic Acids Res. 2008, 36, 3420-3435. [CrossRef]

34. Zhang, F.; Zhou, Y.; Zhang, M.; Luo, X.; Xie, J. Effects of drought stress on global gene expression profile in leaf and root samples of Dongxiang wild rice (Oryza rufipogon). Biosci. Rep. 2017, 37, BSR20160509. [CrossRef]

35. Li, L.Q.; Huang, L.P.; Pan, G.; Liu, L.; Wang, X.Y.; Lu, L.M. Identifying the genes regulated by AtWRKY6 using comparative transcript and proteomic analysis under phosphorus deficiency. Int. J. Mol. Sci. 2017, 18, 1046. [CrossRef]

36. Lu, L.; Qiu, W.; Gao, W.; Tyerman, S.D.; Shou, H.; Wang, C. OsPAP10c $\backslash r$, a novel secreted acid phosphatase in rice, plays an important role in the utilization of external organic phosphorus. Plant Cell Environ. 2016, 39, 2247-2259. [CrossRef]

37. Zhang, J.W.; Xu, L.; Wu, Y.R.; Chen, X.A.; Liu, Y.; Zhu, S.H.; Ding, W.N.; Wu, P.; Yi, K.K. OsGLU3, a putative membrane-bound endo-1,4-beta-glucanase, is required for root cell elongation and division in rice (Oryza sativa L.). Mol. Plant 2012, 5, 176-186. [CrossRef]

38. Secco, D.; Baumann, A.; Poirier, Y. Characterization of the rice PHO1 gene family reveals a key role for OsPHO1;2 in phosphate homeostasis and the evolution of a distinct clade in dicotyledons. Plant Physiol. 2010, 152, 1693-1704. [CrossRef]

39. Chen, X.R.; Chen, M.; He, H.H.; Zhu, C.L.; Peng, X.S.; He, X.P.; Fu, J.R.; Ouyang, L.J. Low-phosphorus tolerance and related physiological mechanism of Xieqingzao B//Xieqingzao B/Dongxiang wild rice $\mathrm{BC}_{1} \mathrm{~F}_{9}$ populations. Chin. J. Appl. Ecol. 2011, 22, 1169-1174.

40. González, E.; Solano, R.; Rubio, V.; Leyva, A.; Paz-Ares, J. Phosphate transporter traffic facilitator1 is a plant-specific sec12-related protein that enables the endoplasmic reticulum exit of a high-affinity phosphate transporter in Arabidopsis. Plant Cell 2005, 17, 3500-3512. [CrossRef]

41. Chen, J.Y.; Wang, Y.F.; Wang, F.; Yang, J.; Gao, M.X.; Li, C.Y.; Liu, Y.Y.; Liu, Y.; Yamaji, N.; Ma, J.F.; et al. The rice CK2 kinase regulates trafficking of phosphate transporters in response to phosphate levels. Plant Cell 2015, 27, 711-723. [CrossRef]

42. Zhang, Q.; Wang, C.; Tian, J.; Li, K.; Shou, H. Identification of rice purple acid phosphatases related to posphate starvation signalling. Plant Biol. 2011, 13, 7-15. [CrossRef]

43. González-Muñoz, E.; Avendaño-Vázquez, A.O.; Montes, R.A.; de Folter, S.; Andrés-Hernández, L.; Abreu-Goodger, C.; Sawers, R.J. The maize (Zea mays ssp. mays var. B73) genome encodes 33 members of the purple acid phosphatase family. Front. Plant Sci. 2015, 6, 341.

44. Segerer, G.; Hadamek, K.; Zundler, M.; Fekete, A.; Seifried, A.; Mueller, M.J.; Koentgen, F.; Gessler, M.; Jeanclos, E.; Gohla, A. An essential developmental function for murine phosphoglycolate phosphatase in safeguarding cell proliferation. Sci. Rep. 2016, 6, 35160. [CrossRef]

45. Segerer, G.; Engelmann, D.; Kaestner, A.; Trötzmüller, M.; Köfeler, H.; Stigloher, C.; Thiele, C.; Jeanclos, E.; Gohla, A. A phosphoglycolate phosphatase/AUM-dependent link between triacylglycerol turnover and epidermal growth factor signaling. Biochim. Et Biophys. Acta (BBA) Mol. Cell Biol. Lipids 2018, 1863, 584-594. [CrossRef]

46. Hyouta, H.; Daisuke, K.; Akira, M. Mechanism of trans-translation revealed by in vitro studies. Front. Microbiol. $2014,5,65$.

47. Zhou, J.; Kang, L.; Liu, C.; Niu, X.; Wang, X.; Liu, H.; Zhang, W.; Liu, Z.; Latgé, J.P.; Yuan, S. Chitinases play a key role in the stipe cell wall extension in the mushroom Coprinopsis cinereal. Appl. Environ. Microbiol. 2019, 85, e00532-19. [CrossRef]

48. Lallena, M.J.; Chalmers, K.J.; Llamazares, S.; Lamond, A.I.; Valcárcel, J. Splicing regulation at the second catalytic step by Sex-lethal involves 3' splice site recognition by SPF45. Cell 2002, 109, 285-296. [CrossRef]

49. Black, D.L. Mechanisms of alternative pre-messenger RNA splicing. Annu. Rev. Biochem. 2003, 72, 291-336. [CrossRef]

50. Perea-Resa, C.; Hernández-Verdeja, T.; López-Cobollo, R.; del Mar Castellano, M.; Salinas, J. LSM proteins provide accurate splicing and decay of selected transcripts to ensure normal Arabidopsis development. Plant Cell 2012, 24, 4930-4947. [CrossRef] 
51. Carrasco-López, C.; Hernández-Verdeja, T.; Perea-Resa, C.; Abia, D.; Catalá, R.; Salinas, J. Environment-dependent regulation of spliceosome activity by the LSM2-8 complex in Arabidopsis. Nucleic Acids Res. 2017, 45, 7416-7431. [CrossRef]

52. Leyval, D.; Uy, D.; Delaunay, S.; Goergen, J.L.; Engasser, J.M. Characterisation of the enzyme activities involved in the valine biosynthetic pathway in a valine-producing strain of Corynebacterium glutamicum. J. Biotechnol. 2003, 104, 241-252. [CrossRef]

53. Xu, L.; Shou, J.Y.; Gill, R.A.; Guo, X.; Najeeb, U.; Zhou, W.J. Effects of ZJ0273 on barley and growth recovery of herbicide-stressed seedlings through application of branched-chain amino acids. J. Zhejiang Univ. Sci. B (Biomed. Biotechnol.) 2019, 20, 71-83. [CrossRef]

54. Shahrtash, M. Plant glutathione S-transferases function during environmental stresses: A review article. Rom. J. Biol. Plant Biol. 2013, 58, 19-25.

55. Kumar, S.; Asif, M.H.; Chkrabrty, D.; Tripathi, R.D.; Dubey, R.S.; Trivedi, P.K. Differential expression of rice Lambda class GST gene family members during plant growth, development, and response to stress conditions. Plant Mol. Biol. Report. 2013, 31, 569-580. [CrossRef]

56. Zheng, L.C.; Zhu, H.B. Bioinformatics analysis on epoxide hydrolase of rice (Oryza sativa). China J. Bioinform. $2009,7,108-112$.

57. Omiecinski, C.J.; Hassett, C.; Hosagrahara, V. Epoxide hydrolase-Polymorphism and role in toxicology. Toxicol. Lett. 2000, 112-113, 365-370. [CrossRef]

58. Lin, S.I.; Chiang, S.F.; Lin, W.Y.; Chen, J.W.; Tseng, C.Y.; Wu, P.C.; Chiou, T.J. Regulatory network of microRNA399 and PHO2 by systemic signaling. Plant Physiol. 2008, 147, 732-746. [CrossRef]

59. Hamburger, D.; Rezzonico, E.; MacDonald-Comber Petétot, J.; Somerville, C.; Poirier, Y. Identification and characterization of the Arabidopsis PHO1 gene involved in phosphate loading to the xylem. Plant Cell 2002, 14, 889-902. [CrossRef]

60. Stefanovic, A.; Ribot, C.; Rouached, H.; Wang, Y.; Chong, J.; Belbahri, L.; Delessert, S.; Poirier, Y. Members of the PHO1 gene family show limited functional redundancy in phosphate transfer to the shoot, and are regulated by phosphate deficiency via distinct pathways. Plant J. 2007, 50, 982-994. [CrossRef]

61. Bari, R.; Datt-Pant, B.; Stitt, M.; Scheible, W.R. PHO2, MicroRNA399, and PHR1 define a phosphate-signaling pathway in plants. Plant Physiol. 2006, 141, 988-999. [CrossRef] 